\title{
HPLC Analysis and Identification of Compounds Inhibiting Bacterial Growth in Ozone Gas Sterilized Polysulfone and Polycarbonate
}

\author{
Hideharu Shintani ${ }^{1 *}$ and Akikazu Sakudo ${ }^{2}$
}

${ }^{1}$ School of Science, Chuo University, 1-13-27, Kasuga, Bunkyo, Tokyo 112-0003, Japan

${ }^{2}$ Laboratory of Biometabolic Chemistry, School of Health Sciences, Faculty of Medicine, University of the Ryukyus, 207 Uehara, Nishihara, Okinawa 903-0215, Japan

\begin{abstract}
Healthcare products must be sterilized before shipping. During sterilization the quality of the products must be maintained. Polysulfone (PS) and polycarbonate (PC) are often used as materials for medical devices. It has been observed that compounds inhibiting bacterial growth are produced when PS or PC are sterilized by autoclaving or by use of ozone gas, especially when ozone gas is used to sterilize PS. This study was conducted to identify the compounds inhibiting bacterial growth. An ethanol extract of the sterilized PS or PC was analyzed by liquid chromatography-moss spectrometry-UV photodiode array $(210-350 \mathrm{~nm})$ for identification and determination of the inhibitors. Bisphenol A, 4,4'-dihydroxydiphenyl sulfone (bisphenol S), and 4-chloro-4'-hydroxydiphenyl sulfone were identified in PS sterilized with ozone gas. Bisphenol A was also identified in PC sterilized with ozone gas. Bisphenol A was not a major inhibitor of bacterial growth because the extent of inhibition did not correlate with the amount of bisphenol A produced. Inhibition by 4-chloro-4'-hydroxydiphenyl sulfone was greater than by bisphenol $\mathrm{S}$ and correlated with the amount produced; the major inhibitor might therefore be 4-chloro-4'-hydroxydiphenyl sulfone. The synergistic effect of bisphenol S and 4-chloro-4'-hydroxydiphenyl sulfone might be a more realistic measure of the exact amount of inhibition.
\end{abstract}

Keywords: Column liquid chromatography; Bisphenol A; 4,4'-dihydroxydiphenyl sulfone (Bisphenol S); 4-chloro-4'hydroxydiphenyl sulfone; Geobocillus stearothermophilus; Micrococcus luteus; Ozone gas sterilization

\section{Introduction}

Several sorts of polymer are used for fabrication of healthcare products. For example, polysulfone (PS) and polycarbonate (PC) arc used to produce the hollow fibers and housing, respectively, of artificial dialyzers [1]. PS is synthesized from 4,4'-dichlorodiphenyl sulfone and bisphenol A sodium salt (Figure 1). PC is synthesized from phosgene and bisphenol A [1-3].

Healthcare products must be sterilized, and sterility must be ensured before shipping. During and after sterilization, the quality of the healthcare products must be maintained. The production of toxic compounds in sterilized healthcare products has already been reported [4,5]. Bisphenol A in sterilized PS and PC is one product formed by sterilization [1]Although the toxicity of bisphenol A and bisphenol S has been reported [6-18], that of 4-chloro-4'-hydroxydiphenyl sulfone has not. This paper is the first to discuss the subject of 4-chloro4'hydroxydiphenyl sulfone in PS sterilized with ozone gas.

After sterilization of PS by autoclaving or with ozone gas, growth of the inoculated bacteria on the sterilized PS was inhibited whereas growth of inoculated bacteria on sterilized PC were not significantly inhibited.

A study has been performed to identify compound(s) inhibiting bacterial growth which might be produced in sterilized PS. For this purpose identification, determination, and bioassay study of the inhibiting compounds were conducted by liquid chromatographymass spectrometry (LC-MS) in combination with UV photodiodearray detection.

\section{Experimental}

\section{Materials}

The hydrophilic polysulfones (PS) were from Nihon Pall, Nihon
Millipore, and Sartorius. The hydrophilic polycarbonate (PC) and hydrophobic polyvinylidene difluoride (PVDF) were from Nihon Millipore. Ozone gas for sterilization was from an M6 Ozonizer (Ishikawajima Harima Heavy Industry). 4,4'-Dichlorodiphenyl sulfone, 4,4'-dihydroxydiphenyl sulfone (bisphenol S), bisphenol A, and phosgene were from Tokyo Kasei (Tokyo, Japan). 4-Chloro4'-hydroxydiphenyl sulfone, which was newly found in PS sterilized with ozone gas, was synthesized by Shintani. The synthetic procedure is described in the Result and Discussion section. Purified water and ethanol for high-performance liquid chromatography were HPLC grade from Tokyo Kasei.

\section{Sterilization and measurement of inhibition of bacterial growth}

During sterilization with ozone the amount of the gas in the chamber was measured by means of an EG-2001 ozone monitor (Ebara Jitsugyo) [19]. Autoclave sterilization was conducted at $121.1^{\circ} \mathrm{C}$ for $15 \mathrm{~min}$. The bacteria used for inoculation were Geobacillus stearothermophilus ATCC 7953 spore-forming bacteria and Micrococcus luteus nonspore-forming bacteria. The populations were approximately 10 to $10^{3}$ colony forming units (CFU). The bacteria were cultivated in soybean casein digest agar (SCDA) as culture medium; this was cultivated at $55^{\circ} \mathrm{C}$ for $\mathrm{G}$. stearothermophilus and at $30^{\circ} \mathrm{C}$ for $\mathrm{M}$. luteus. The cultivation period was validated for seven consecutive days. Samples of non-sterilized and sterilized PS or PC were immersed separately in 4

*Corresponding author: Hideharu Shintani, 1-10-60, Minamidaira, Hino, Tokyo 191-0041 Japan, Tel: 042-592-2336; E-mail: shintani@mail.hinocatv.ne.jp

Received July 14, 2011; Accepted August 22, 2011; Published August 24, 2011

Citation: Shintani H, Sakudo A (2011) HPLC Analysis and Identification of Compounds Inhibiting Bacterial Growth in Ozone Gas Sterilized Polysulfone and Polycarbonate. Pharm Anal Acta 2:130. doi:10.4172/2153-2435.1000130

Copyright: ( $) 2011$ Shintani H, et al. This is an open-access article distributed under the terms of the Creative Commons Attribution License, which permits unrestricted use, distribution, and reproduction in any medium, provided the original author and source are credited. 
$\mathrm{mL}$ ethanol for one day at the room temperature and $5 \mu \mathrm{L}$ of the extract obtained was analyzed by HPLC.

\section{Liquid chromatography-mass spectrometry}

LC-MS was performed with a 2790 separation module, a ZQ 2000 mass detector, and a 996 photodiode array (PDA) detector, as third dimension UV detector, all from Waters. The detection wavelength range of the PDA was from 210 to $350 \mathrm{~nm}$. Compounds were separated on a $2.1 \mathrm{~mm}$ i.d. x $150 \mathrm{~mm}, 3.5 \mu \mathrm{m}$ particle, Symmetry C-18 column from Waters; the column temperature was maintained at $40^{\circ} \mathrm{C}$. The mobile phase was linear gradient from 10:90 to 90:10 (v/v) ethanoldistilled water in $30 \mathrm{~min}$ then back to the initial conditions in $5 \mathrm{~min}$. The total run time for the analysis was thus $35 \mathrm{~min}$. The flow rate was $0.2 \mathrm{~mL} / \mathrm{min}$ and the injection volume was $5 \mu \mathrm{L}$.

Mass spectrometry (MS) was performed with a capillary voltage of $3.50 \mathrm{kV}$. The gas flow removing the mobile phase was $400 \mathrm{~L} / \mathrm{h}$ at $350^{\circ} \mathrm{C}$, the cone gas flow rate was $50 \mathrm{~L} / \mathrm{h}$, and the ion source temperature was $100^{\circ} \mathrm{C}$. MS data were acquired by scanning the spectrometer between $\mathrm{m} / \mathrm{z} 100$ and $1000 \mathrm{Da}$; the scan time was 0.5 second and the cone voltage was $30 \mathrm{~V}$ for both positive and negative electrospray ionization (ESI).

\section{Result and Discussion}

Formation of 4-Chloro-4'Hydroxydiphenyl Sulfone, 4,4'-Dihydroxydiphenyl Sulfone (bisphenol S), and Bisphenol A in Sterilized PS

The new compound 4-chloro-4'-hydroxydiphenyl sulfone was synthesized by reacting $4,4^{\prime}$-dichlorodiphenyl sulfone with a molar equivalent of potassium hydroxide. The reactants were dissolved in a 1:1 $(\mathrm{v} / \mathrm{v})$ mixture of chloroform and water, the water layer was discarded, and the chloroform layer was separated and evaporated. The major product in the chloroform layer was 4-chloro-4'-hydroxydiphenyl sulfone. The white powder of the synthesized 4-chloro-4'-hydroxydiphenyl sulfone was $99.9 \%$ pure according to HPLC analysis (C-18 column, 1:1 ethanol-water as mobile phase, $215 \mathrm{~nm}$ detection, data not shown). The mass spectrum and chemical structure of this compound are presented in Figure 2. This compound was typically formed in PS sterilized with ozone gas, but not in PS sterilized by autoclaving, with ethylene oxide gas, with hydrogen peroxide gas, by gamma-ray irradiation, by electron beam irradiation or by UV irradiation. The compound was not produced in PC sterilized with ozone gas.

The mass spectrum and chemical structure of 4,4'-dihydroxydiphenyl sulfone (bisphenol S) are presented in Figure 3. The mechanism of formation of this compound is identical with that of 4-chloro-4'-hydroxydiphenyl sulfone described above. The formation of bisphenol A in PS and PC sterilized with ozone gas, by autoclaving, with hydrogen peroxide gas, by gamma-ray irradiation, or by electron beam irradiation has already been reported [1].

Mechanism of Formation of 4-Chloro-4'-hydroxydiphenyl Sulfone, 4,4'-Dihydroxydiphenyl Sulfone (Bisphenol S), and Bisphenol A in Sterilized PS

The major chemical component in ozone gas sterilization is $\mathrm{OH}$. (the hydroxy radical) which has a large oxidation-reduction potential $(2.07 \mathrm{~V})$. The oxidation-reduction potential of hydrogen peroxide gas is $1.77 \mathrm{~V}$. The main reactant in hydrogen peroxide gas sterilization is also the hydroxy radical, but 4-chloro-4'-hydroxydiphenyl sulfone is not formed in PS sterilized with hydrogen peroxide gas, in contrast with PS sterilized with ozone gas. The difference might be because of the different oxidation-reduction potential and/or $\mathrm{OH}$ radical amount.

The formation of 4-chloro-4'-hydroxydiphenyl sulfone in PS sterilized with ozone gas is a result of successive cleavage of the ether linkage with the terminal chloride in PS in one side of the chemical structure (Figure 1). In contrast, 4,4'-dihydroxydiphenyl sulfone (bisphenol S) is produced by simultaneous cleavage at both ether linkages of PS (Figure 1).

Bisphenol A can originate in two ways. It might be a residue of the starting material in the fabrication of PS and PC or it might arise from simultaneous cleavage of both ether linkages of PS or PC by the $\mathrm{OH}$ radical (Figure 1). The latter possibility might be correct, because if the former speculation is correct it is difficult to explain the absence of 4,4'-dichlorodiphenyl sulfone or phosgene residues in unsterilized and sterilized PS or PC, respectively. In addition no bisphenol A peak has been observed at a retention time $\left(t_{R}\right)$ of $18.01 \mathrm{~min}$ in unsterilized and autoclave-sterilized PS and PC (Figures 4 and 5). Bisphenol A was only observed in PS and PC sterilized with ozone gas (Figure 6). These results indicate that bisphenol A was produced by simultaneous cleavage of both ether linkages by the $\mathrm{OH}$ radical produced from the ozone gas.

The mass spectrum and UV spectrum of the compounds of $t_{R}$ 11.08 and $17.28 \mathrm{~min}$ in Figure 6 were identical with those of authentic samples of bisphenol S and 4-chloro-4'-hydroxydiphenyl sulfone.

This is the rationale for identification of these compounds. The mass spectra of 4-chloro-4'-hydroxydiphenyl sulfone, 4,4'-dihydroxydiphenyl sulfone (bisphenol S) in Figures 2 and 3, respectively, are explained as follows. In the mass spectrum of bisphenol $\mathrm{S}\left(\mathrm{OH}-\varphi-\mathrm{SO}_{2}-\varphi-\mathrm{OH}\right.$, Figure 3$)$ the fragment of mass 251.1 was $\mathrm{Mw}+1$, that at 273 was $\mathrm{Mw}+\mathrm{Na}$, and that at mass $157\left(\mathrm{O}_{2} \mathrm{~S}-\varphi \mathrm{OH}\right)$ was formed by cleavage of the bond between benzene and $\mathrm{SO}_{2}$.

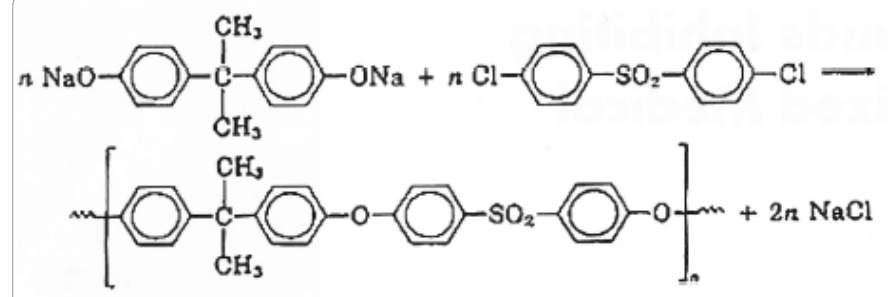

Figure 1: Synthesis of PS

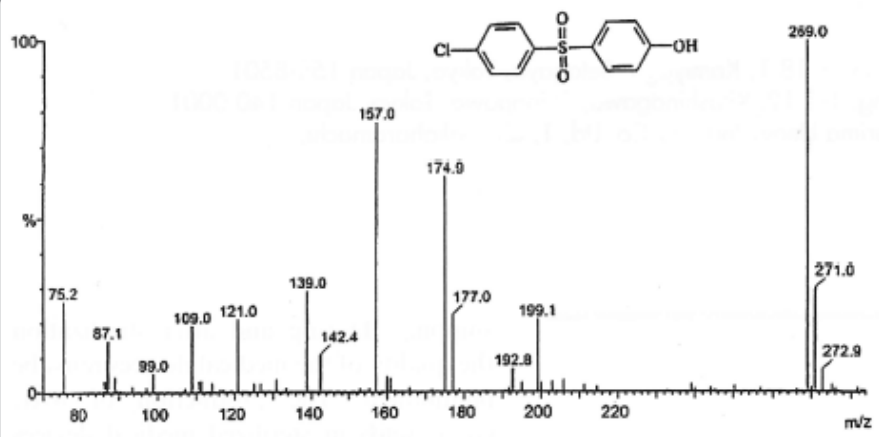

Figure 2: Mass spectrum and chemical structure of 4-chloro-4'-hydroxydiphenyl sulfone. (The chemical structure of 4-chloro-4'-hydroxydiphenyl sulfone can be depicted as $\left.\mathrm{OH}-\varphi-\mathrm{SO}_{2}-\varphi-\mathrm{Cl}\right)$. 
In the mass spectrum of 4-chloro-4'hydroxydiphenyl sulfone $(\mathrm{OH}-$ $\varphi-\mathrm{SO}_{2}-\varphi-\mathrm{Cl}$, Figure 2) the fragment at $\mathrm{m} / \mathrm{z} 269$ was $\mathrm{Mw}+1$, that at 271 was an isotope fragment of $\mathrm{Mw}+1$, that at 290.9, was $\mathrm{Mw}+\mathrm{Na}$, that at 293.1 was the isotope fragment of $\mathrm{Mw}+\mathrm{Na}$, that at $174.9\left(\mathrm{O}_{2} \mathrm{~S}-\varphi-\mathrm{Cl}\right)$ was formed by cleavage of the bond between phenol and $\mathrm{SO}_{2}$, that at 177 was the isotope fragment of $\mathrm{O}_{2} \mathrm{~S}-\varphi-\mathrm{Cl}$, and that at 157 was formed by cleavage of the bond between chlorobenzene and $\mathrm{SO}_{2}\left(\mathrm{O}_{2} \mathrm{~S}-\varphi-\mathrm{OH}\right)$.

\section{Ozone gas sterilization}

The result from sterilization with ozone gas was confirmed by use

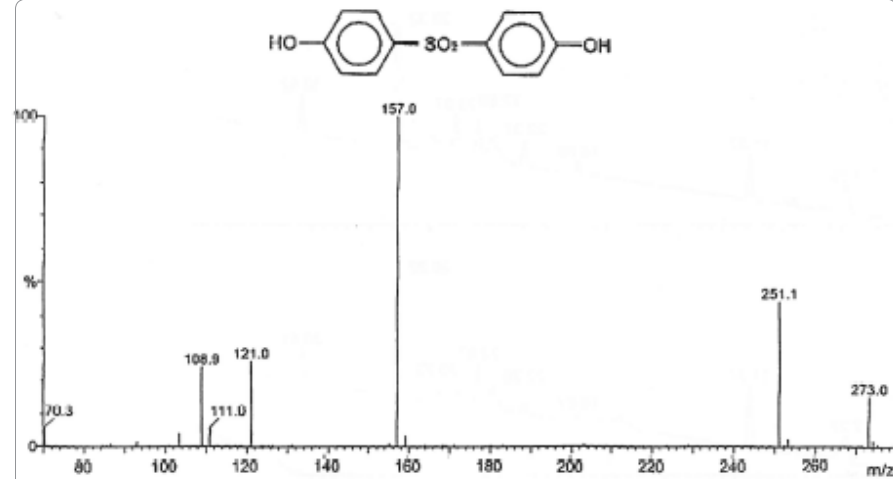

Figure 3: Mass spectrum and chemical structure of 4,4'-dihydroxydipheny sulfone (bisphenol S). (The chemical structure of 4,4'-dihydroxydiphenyl sulfone (bisphenol S) can be depicted as $\mathrm{OH}-\varphi-\mathrm{SO}_{2}-\varphi-\mathrm{OH}$.).
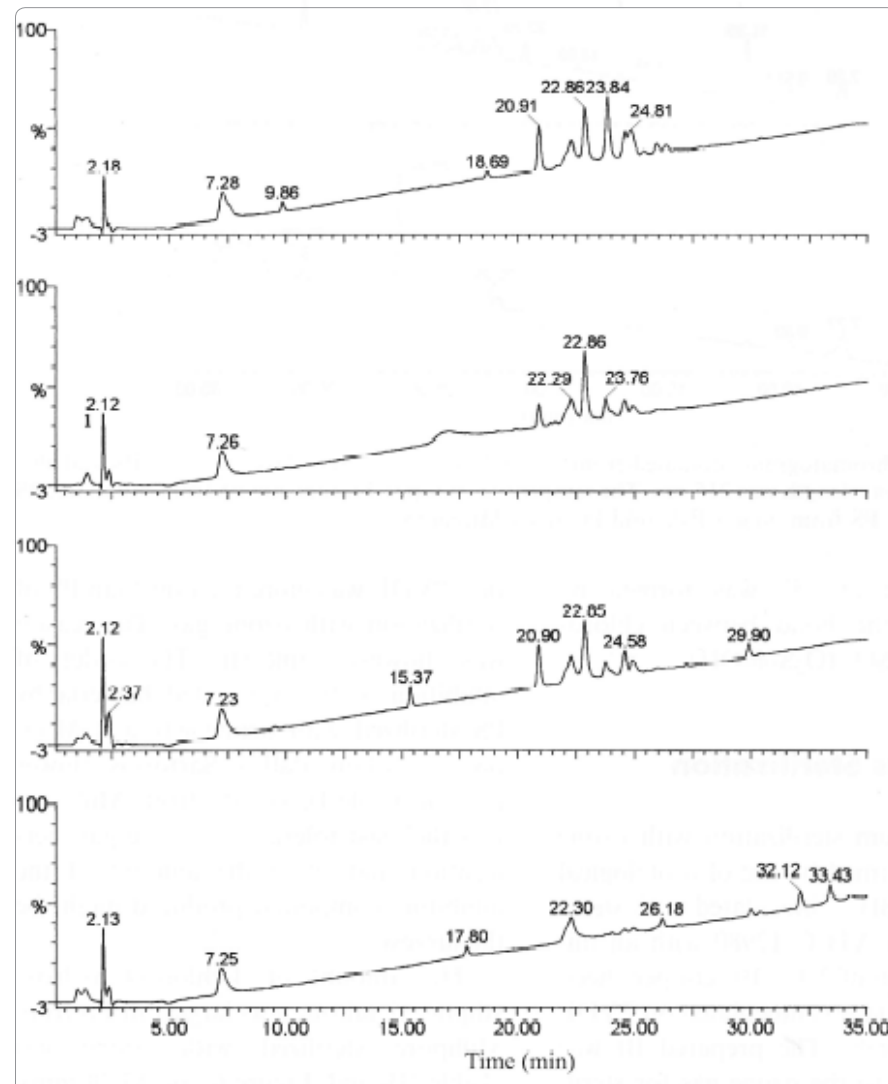

Figure 4: LC chromatograms obtained from ethanol extracts of unsterilized PS and PC. The detection wavelength was $215 \mathrm{~nm}$. The samples, from top to bottom, are PS from Millipore, PS from Sartorius, PS from Nihon Pall, and PC from Millipore.
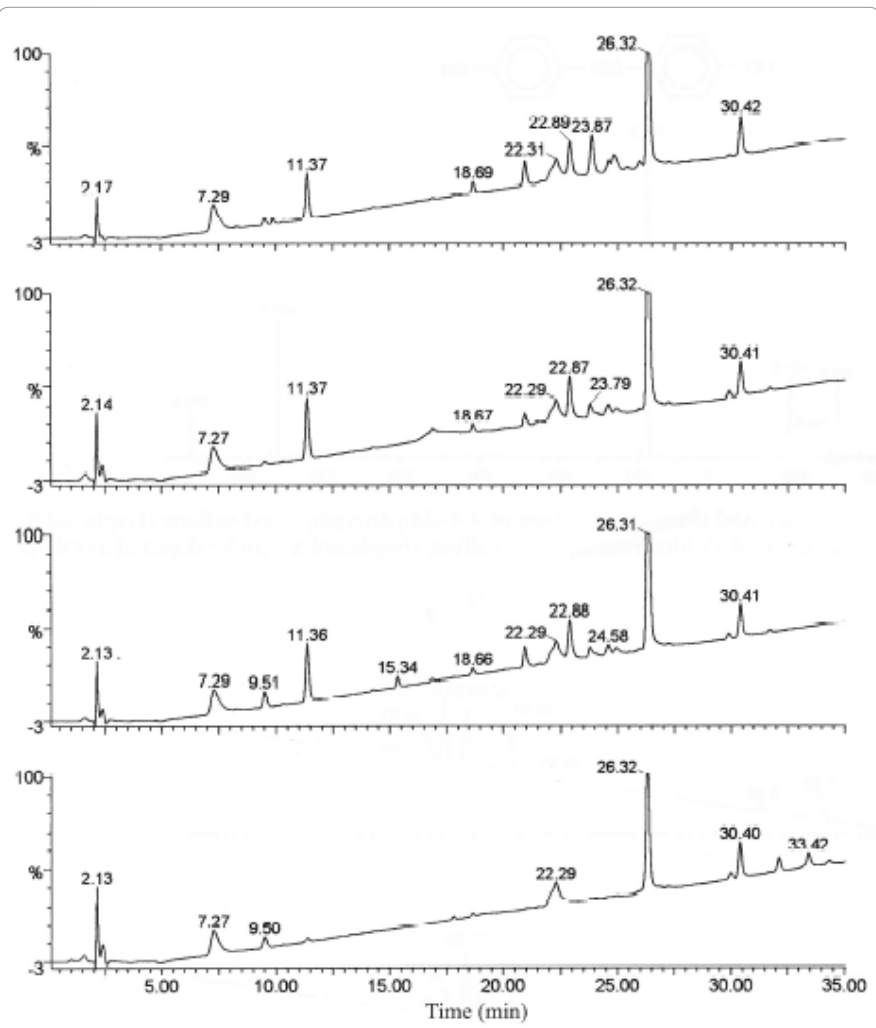

Figure 5: LC chromatograms obtained from ethanol extracts of autoclavesterilized PS and PC. The detection wavelength was $215 \mathrm{~nm}$. The samples, from top to bottom, are PS from Millipore, PS from Sarlorius, PS from Nihon Pall, and PC from Millipore.

of a biological indicator (BI) inoculated G. stearothermophills ATCC 7953 with an initial population of $2.4 \times 10^{3} \mathrm{CFU}$ per sheet. The BI bacterium was inoculated on PVDF or PS separately. The prepared BI was then exposed to the ozone gas for sterilization for $20 \mathrm{~min}$ or 50 min. The results are presented in Table 1 . The sporeforming bacterium G. stearothermophills ATCC 7953 survived completely when inoculated on PVDF but was completely inhibited when inoculated on PS under identical conditions of sterilization with ozone gas for 50 min (upper part of Table 1). It can be speculated that compound(s) inhibiting bacterial growth are produced in PS sterilized with ozone gas, in contrast with PVDF sterilized with ozone gas. The results in Table 1 show that PVDF was more tolerant than PS of sterilization with ozone gas. The reason was however unclear. The order of inhibition of the inoculated bacteria by PS sterilized with ozone gas was Millipore> Nihon Pall> Sartorius (lower part of Table 1), i.e. PS from Millipore was the least tolerant of ozone gas sterilization, indicating the amount of the inhibiting compound produced might be the largest.

The amount of 4-chloro-4'-hydroxydiphenyl sulfone was largest in PS from Millipore sterilized with ozone gas (Table 3 and Figure 6, $t_{R}$ $17.28 \mathrm{~min}$ ). This is most likely to be the compound inhibiting bacteria growth.

The lower part of Table 1 indicates that bacteria inoculated on PC from Millipore were more inhibited than on PS from Nihon Pall or Sartorius. This order of inhibition cannot be explained by the amount of bisphenol A formed (Table 3), because if bisphenol A is the major inhibitor of bacterial growth, inhibition by PS from Sartorius should 
be greatest (Table 3), which is not correct (Table 1 and Table 3). In addition the level of bisphenol A is lowest in PS from Millipore (Table III) but the extent of inhibition by PS from Millipore is the greatest (Table 1). The result in Table 1 cannot be explained in terms of the amount of bisphenol A produced. They can, however, be explained in terms of chemicals other than bisphenol A.

\section{Cultivation of inoculated bacteria on sterilized PS}

Spores of G. stearothermophilus ATCC 7953 and vegetative cells of M. luteus were inoculated on PS from Milipore previously sterilized by autoclaving $\left(121.1^{\circ} \mathrm{C}\right.$ for $\left.15 \mathrm{~min}\right)$ or by treatment with ozone gas (3000 ppm, 80\% relative humidity, RH, $15 \mathrm{~min}$ ). The results obtained are presented in Table 2; they show that no significant inhibition of inoculated G. stearothermophilus could be observed on autoclavesterilized PS. In contrast, approximately half of the inoculated G. stearothermophilus was inhibited on the PS sterilized with ozone gas. Slight inhibition of inoculated M. luteus on autoclave-sterilized PS was observed (Table 2). Inoculated M. luteus was totally inhibited on PS sterilized with ozone gas (Table 2).

One difference between G. stearothermophilus and M. luteus is that the former is spore forming whereas the latter is not. The nonpore-forming bacteria were less tolerant of ozone gas sterilization [19] (Figure 7). The slight inhibition of M. luteus observed for autoclave sterilization (Table 2) can be explained in terms of the different peaks eluting in Figure 4 and Figure 5. For example, peaks of $t_{R} 11.37,26.32$
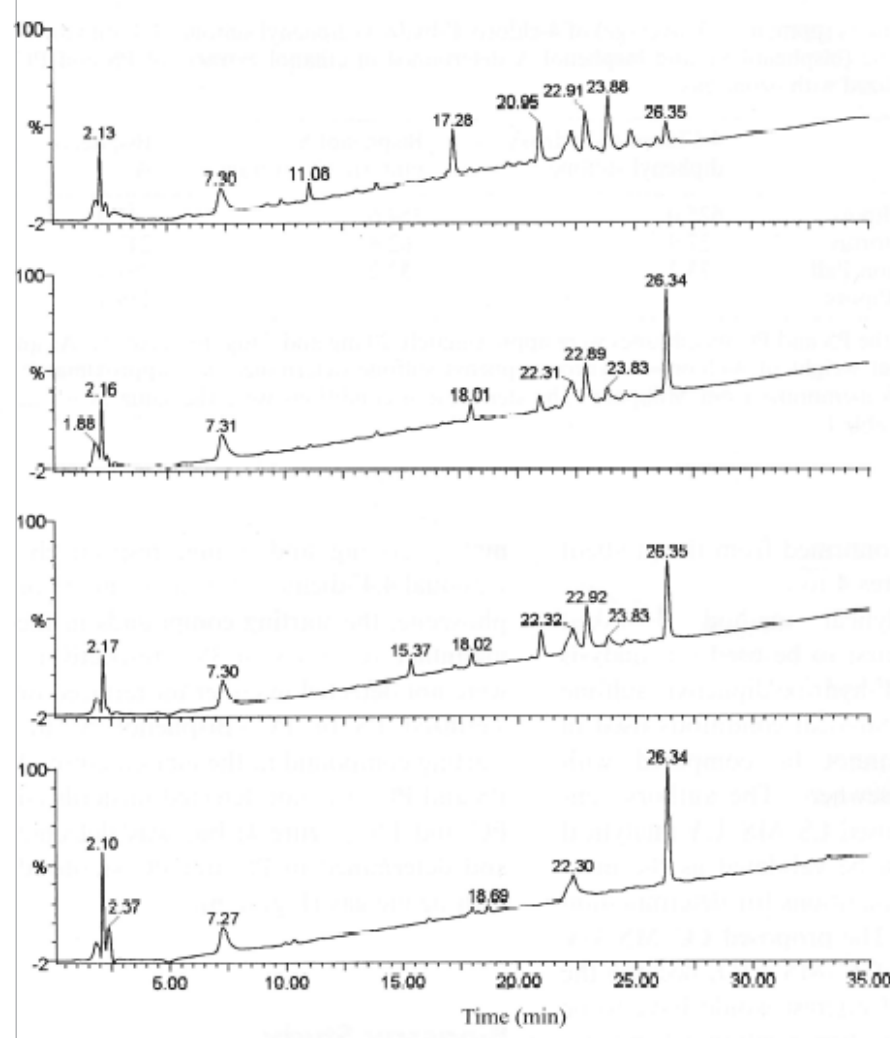

Figure 6: LC chromatograms obtained from ethanol extracts of PS sterilized with ozone gas and PC. The detection wavelength was $215 \mathrm{~nm}$. The peaks at $t_{R} 18.01,17.28$, and $11.08 \mathrm{~min}$ are those of bisphenol $\mathrm{A}, 4$-chloro-4'hydroxydiphenyl sulfone, and 4,4'-dihydroxydiphenyl sulfone (bisphenol S), respectively. The samples, from top to bottom, are PS from Millipore, PS from Sartorius, PS from Nihon Pall, and PC from Millipore.

\begin{tabular}{|c|c|c|}
\hline & Mieroorganism & Examples \\
\hline \multirow[t]{13}{*}{$\begin{array}{c}\text { More } \\
\text { Resistant }\end{array}$} & Prions & $\begin{array}{l}\text { Scrapie, Creutzfeldt-Jakob disease, chronic } \\
\text { wasting disease }\end{array}$ \\
\hline & Bacterial spores & Bacillus, Geobacillus, Clostridium \\
\hline & Protozoal oocysts & Cryptosporidium \\
\hline & Helminth eggs & Ascaris, Enterobius \\
\hline & Mycobacteria & $\begin{array}{l}\text { Mycobacterium tuberculosis, M. terrae, } M \text {. } \\
\text { chelonae }\end{array}$ \\
\hline & Small, nonenveloped viruses & Poliovirus, Parvoviruses, Papilluntraviruses \\
\hline & Protozoal cysts & Giardia, Acanthamoeba \\
\hline & Fungal spores & Aspergillus, Penicillium \\
\hline & Gram-negative bacteria & Pseudomonas, Providencia, Escherichia \\
\hline & Vegetative fungi and algae & $\begin{array}{l}\text { Aspergillus, Trichophyton, Candida, } \\
\text { Chlamydomonas }\end{array}$ \\
\hline & Vegetative helminths and protozoa & Ascaris, Cryptosporidium, Giardia \\
\hline & Large, nonenveloped viruses & Adenoviruses, rotaviruses \\
\hline & Gram-positive bacteria & Staphyiococcus, Streptococcus, Enterococcus \\
\hline $\begin{array}{c}\text { Less } \\
\text { Resistant }\end{array}$ & Enveloped viruses & HIV, hepatitis B virus, herpes simplex virus \\
\hline
\end{tabular}

Figure 7: Tolerance order of sterilization.

and $30.4 \mathrm{~min}$ in Figure 5 might be candidate inhibitors from autoclave sterilization: the extent of inhibition by these compound was not significant, however (Table 2). In addition these peaks were smaller for PS sterilized with ozone gas (Figure 6).

\section{LC-UV chromatograms after sterilization by autoclaving or with Ozone Gas}

LC-UV chromatogram obtained from ethanol extract of PS or PC after no sterilization, after sterilization by autoclaving, or after sterilization with ozone gas, with detection at $215 \mathrm{~nm}$, are presented in Figures 4 to 6 , respectively. The y axis sensitivity is identical in these figures, enabling direct comparison of peak areas. When the chromatograms presented in Figures 4 to 6 are compared it is apparent peaks of $t_{R} 11.08,17.28$, and $18.01 \mathrm{~min}$ are characteristic peaks in Figure 6. The chemical structures of the compounds generating these peaks were studied by mass spectrometry (Figures 2 and 3) and the compounds were identified as 4,4'-dihydroxydiphenyl sulfone (bisphenol S, Figure 3), 4-chloro-4'-hydroxydiphenyl sulfone (Figure 2), and bisphenol A, in order of elution. 4,4'-Dichlorodiphenyl sulfone or phosgene, the starting compounds in the fabrication of PS or PC, respectively were not detected in Figures 4 to 6.

An authentic sample of bisphenol A was analyzed by LC-MS to determine whether or not the peak of $t_{R} 18.01$ min was bisphenol $A$. For the authentic sample of bisphenol $A t_{R}$ was $18.01 \mathrm{~min}$ and the mass spectra of the authentic sample and that obtained from the peak at $t_{R}$ $18.01 \mathrm{~min}$ were identical. This indicated that the peak at $t_{R} 18.01 \mathrm{~min}$ in Figure 6 was bisphenol A. The UV spectra of authentic bisphenol A and that obtained from the peak of $t_{R} 18.01 \mathrm{~min}$ in Figure 6 were also identical. The UV wavelength of maximum absorbance of 4-chloro-4'hydroxydiphenyl sulfone was $257.7 \mathrm{~nm}$; those of bisphenol S were 231.7 $\mathrm{nm}$ and $258.7 \mathrm{~nm}$. Absorption at both $257.7 \mathrm{~nm}$ and $258.7 \mathrm{~nm}$ was because of the presence of the benzene ring in the chemical structure.

The linear gradient used for LC-MS-UV analysis was shown to afford optimum conditions for the most appropriate and reproducible baseline separation in simultaneous analysis of bisphenol S $\left(t_{R} 11.08\right.$ min), 4-chloro-4'-hydroxydiphenyl sulfone ( $\left.t_{R} 17.28 \mathrm{~min}\right)$, and bisphenol A ( $\left.t_{R} 18.01 \mathrm{~min}\right)$. Baseline separation of these peaks was satisfactory and free from matrix effects (Figure 6). This was confirmed by performing replicate experiments using ten samples. 
The standard calibration plots for these compounds under these analytical conditions were linear from zero to $2000 \mathrm{ppm}$ and the correlation coefficients $(r)$ of the standard calibration plots were 0.99 . The limit of determination of these compounds at $260 \mathrm{~nm}$ was 0.02 $\mathrm{ppb}$, which was satisfactory for determination in this experiment at ppm levels (Table 3 ). The reproducibility of the linear gradient run was satisfactory $(n=10)$. This can be confirmed from the gradient slope of Figures 4 to 6 .

The analytical method described herein is the first to be used for analysis of 4-chloro-4'-hydroxydiphenyl sulfone and so the analytical conditions used in this work cannot be compared with those used elsewhere. The authors confirm the proposed LS-MS-UV analytical procedure will be validated as the most appropriate conditions for determination and analysis. The proposed LC-MS-UV is superior to GC-MS-FID, because the compounds of interest would have to be derivatized for vaporization when analyzed by GC. Such a derivatization procedure might cause significant variation of the amount determined. Even though UV absorption spectrometry is not selective and has lower sensitivity than ECD, LC-MS-UV is more appropriate for the analysis of unknown compounds. UV detection at $260 \mathrm{~nm}$ was superior

\begin{tabular}{|c|c|c|c|c|c|c|}
\hline Sterilization period & \multicolumn{2}{|c|}{ Carrier materials } & \multicolumn{4}{|l|}{ Result } \\
\hline \multirow[t]{4}{*}{$50 \mathrm{~min}$} & \multicolumn{2}{|c|}{ PVDF from Millipore } & \multicolumn{4}{|c|}{ All positive in a total of 10 samples } \\
\hline & \multicolumn{2}{|c|}{ PS from Millipore } & \multicolumn{4}{|c|}{ All negative in a total of 10 samples } \\
\hline & \multicolumn{2}{|c|}{ PS from Nihon Pall } & \multicolumn{4}{|c|}{ All negative in a total of 10 samples } \\
\hline & \multicolumn{2}{|c|}{ PS from Sartorius } & \multicolumn{4}{|c|}{ All negative in a total of 10 samples } \\
\hline \multirow[t]{4}{*}{$20 \mathrm{~min}$} & \multicolumn{2}{|c|}{ PS from Sartorius } & \multicolumn{4}{|c|}{ All positive in a total of 10 samples } \\
\hline & \multicolumn{2}{|c|}{ PS from Nihon Pall } & \multicolumn{4}{|c|}{ Two negative samples in 10 samples } \\
\hline & \multicolumn{2}{|c|}{ PC from Millipore } & \multicolumn{4}{|c|}{ Six negative samples in 10 samples } \\
\hline & \multicolumn{2}{|c|}{ PS from Millipore } & \multicolumn{4}{|c|}{ All negative in a total of 10 samples } \\
\hline \multicolumn{7}{|c|}{$\begin{array}{l}\text { Sterilization condition:ozone gas concentration } 3000 \mathrm{ppm} \text {, relative humidity }(\mathrm{RH}) \\
80 \% \text {, temperature } 35 \mathrm{oC} \text {, microorganism G. stearothermophilus ATCC } 7953 \text {, } \\
2.4 \times 10^{3} \text { CFU/sheet PVDF: polyvinylidene difluoride, PS: polysulfone, PC: } \\
\text { polycarbonate }\end{array}$} \\
\hline \multicolumn{7}{|c|}{ Table 1: Results from sterilization obtained by use of a biological indicator (BI). } \\
\hline \multicolumn{2}{|l|}{ Bacteria } & \multicolumn{5}{|c|}{ Population (CFU) } \\
\hline \multirow{3}{*}{\multicolumn{2}{|c|}{ G. stearothermophilus }} & Initial & & 25 & 25 & 25 \\
\hline & & Autoclave & e sterilization & 28 & 21 & 27 \\
\hline & & Ozone ge & as sterilization & 11 & 11 & 17 \\
\hline \multirow[t]{3}{*}{ M. luteus } & & Initial & & 34 & 34 & 34 \\
\hline & & Autoclave & sterilization & 31 & 27 & 27 \\
\hline & & Ozone ge & as sterilization & 0 & 0 & 0 \\
\hline
\end{tabular}

Autoclaving was conducted at $121.1^{\circ} \mathrm{C}$ for $15 \mathrm{~min}$. The concentration of ozone gas was $3000 \mathrm{ppm}$ for $15 \mathrm{~min}$. RH $80 \%$. PS is polysulfone.

Table 2: $\quad$ Results from cultivation of inoculated G. stearothermophilus ATCC 7953 or M. luteus onto PS from Millipore sterilized by autoclaving or by use of ozone gas.

\begin{tabular}{|l|r|r|r|}
\hline Material & $\begin{array}{l}\text { 4-chloro-4'-hydroxy } \\
\text { diphenyl sulfone }\end{array}$ & bisphenol S & bisphenol A \\
\hline PS from Millipore & 625.0 & 354.6 & 42.9 \\
\hline PS from Saltorius & 27.9 & 62.8 & 247.0 \\
\hline PS from Nihon Pall & 73.2 & 32.2 & 207.4 \\
\hline PC from Millipore & - & - & 119.1 \\
\hline
\end{tabular}

The weights of the PS and PC membrane were approximately $20 \mathrm{mg}$ and 7 $\mathrm{mg}$, respectively. As an example, the net weight of 4-chloro-4'-hydroxydiphenyl sulfone determined was approximately $12 \mu \mathrm{g}$ in the PS membrane from Millipore. The sterilization conditions were the same as in the lower part of Table 1.

Table 3: Amounts (ppm, $\mathrm{n}=3$ average) of 4-chloro-4'-hydroxydiphenyl sulfone, 4,4'-dihydroxydiphenyl sulfone (bisphenol S), and bisphenol A determined in ethanol extracts of PS and PC sterilized with ozone gas. to detection at $215 \mathrm{~nm}$, because of selective detection of compounds with a benzene ring such as 4-chloro-4'-hydroxydiphenyl sulfone, 4,4'-dihydroxydiphenyl sulfone (bisphenol S), and bisphenol A. All have the benzene ring in their chemical structure. The authors detected both at $215 \mathrm{~nm}$ and $260 \mathrm{~nm}$.

\section{Determination of 4-Chloro-4'hydroxydiphenyl Sulfone, 4,4'-Dihydroxydiphenyl Sulfone (Bisphenol S) and Bisphenol A}

The amounts of these compounds determined are presented in Table 3. Analyses were performed in triplicate and the data presented are averages. The sample weights of PS and PC were approximately 20 $\mathrm{mg}$ and $7 \mathrm{mg}$, respectively. Residual 4,4'-dichlorodiphenyl sulfone or phosgene, the starting compounds in the manufacture of PS or PC, respectively, were not detected in either unsterilized or sterilized PS or PC. Bisphenol A, the starting compound in the manufacture of PS and PC, was not detected unsterilized PC and PS (Figure 4) but was detected and determined in PS and PC sterilized with ozone gas (Figure 6).

\section{Bioassay study}

The amount or 4-chloro-4'-hydroxydiphenyl sulfone determined in PS from Millipore (625 ppm, Table 3) was dissolved in $1 \mathrm{~mL}$ ethanol. Unsterilized PS membrane from Nihon Pall was immersed in the $1 \mathrm{~mL}$ ethanol solution containing the 4-chloro-4'-hydroxydiphenyl sulfone so that the membrane was evenly coated. The PS membrane was then dried. After drying, 30 CFU/10 $\mu \mathrm{L}$ of G. stearothermophilus ATCC 7953 and M. luteus were separately applied to the treated PS membrane. The membranes containing the 4-chloro-4'-hydroxydiphenyl sulfone and the bacteria were cultured for seven consecutive days in SCDA at $55^{\circ} \mathrm{C}$ for G. stearothermophilus ATCC 7953 and at $30^{\circ} \mathrm{C}$ for M. luteus. The bioassay result was that approximately half of G. stearothermophilus ATCC 7953 survived whereas M. luteus was totally inhibited.

\section{Inhibition compounds}

As shown in Table 1 and Table 3, the order of inhibition of the inoculated bacteria was: PS from Millipore $>$ PC from Millipore $>$ PS from Nihon Pall $>$ PS from Sartrius. This order was not successfully explaied by the relative amounts of bisphenol A in Table 3. 4,4'-Dichlorodiphenyl sulfone is not used for fabrication of $\mathrm{PC}$, thus production of bisphenol $\mathrm{S}$ and 4-chloro-4'-hydroxydiphenyl sulfone was not observed in PC sterilized with ozone gas -only bisphenol A was observed in PC sterilized in this way (Figure 6). No residual phosgene was observed in sterilized PC after any of the sterilization procedures (Figures 4 to 6).

The amounts of 4-chloro-4'-hydroxydiphenyl sulfone produced coincided with the order of inhibition: PS from Millipore> PS from Nihon Pall > PS from Sartorius (Table 3); this compound might, therefore, be the major inhibitor. As an alternative, the synergistic effect of bisphenol S and 4-chloro-4'hydroxydiphenyl sulfone (Table 3) did coincide with the order of inhibition: PS from Millipore $>$ PS from Nihon Pall $>$ PS from Sartorius (lower part of Table 1). The amount of bisphenol $S$ produced did not coincide with the order of inhibition: PS from Millipore > PS from Nihon Pall > PS from Sartorius (Table III), therefore bisphenol $\mathrm{S}$ alone cannot be the major inhibitor of bacterial growth.

The synergistic effect of the 4-chloro-4'-hydroxydiphenyl sulfone and bisphenol $\mathrm{S}$ might explain inhibition of bacterial growth more realistically, but this is difficult to assess. Bisphenol A might not result in significant inhibition even though it is known to be an endocrine 
Citation: Shintani H, Sakudo A (2011) HPLC Analysis and Identification of Compounds Inhibiting Bacterial Growth in Ozone Gas Sterilized Polysulfone and Polycarbonate. Pharm Anal Acta 2:130. doi:10.4172/2153-2435.1000130

disrupter. This is because the amount of bisphenol A produced did not correlate with the order of inhibition (Table 1 and Table 3).

\section{Conclusion}

PS, PC, and PVDF are often used as materials for fabrication of healthcare products. When PS was sterilized by autoclaving slight inhibition of bacterial growth was observed. When PS was sterilized with ozone gas significant inhibition of the bacterial growth was observed. PVDF might be the most appropriate material for the medical use. According to LC-MS-UV and bioassay studies, the major inhibitor might be 4-chloro-4'-hydroxydiphenyl sulfone and/or a combination of 4-chloro-4'-hydroxydiphenyl sulfone and bisphenol S. Bisphenol S alone cannot not be the major inhibitor. The inhibiting effect of bisphenol A on bacterial growth might not be significant.

\section{References}

1. Shintani $H$ (2001) Chromatographia 53: 331-333.

2. Shintani H (1995) J Liq Chromatogr 18: 613-626.

3. Suzuki K, Ishikawa K, Sugiyama K, Furuta H, Nishimura F (2000) Dent Mater J 19: 389-395

4. Shintani H (1995) Biomed Instrum Techno 129: 513-519.

5. Shintani H (1995) J Biomater Appl 10: 23-58.
6. Chen MY, Ike M, Fujita M (2002) Environ Toxicol 17: 80-86.

7. Kanai H, Barrett JC, Metzler M, Tsutsui T (2001) Int J Cancer 93: 20-25.

8. Nakagawa Y, Tayama S (2000) Arch Toxicol 74: 99-105.

9. Pfeiffer E, Rosenberg B, Deuschel S, Metzler M (1997) Mutat Res 390: 21-31.

10. Wang JL, Buhler DR (1981) J Toxicol Environ Health 8:639-648.

11. Tsutsui T, Tamura $Y$, Suzuki A, Hirose $Y$, Kobayashi M, Nishimura H, Metzler M, Barrett JC (2000) Int J Cancer 15:151-154.

12. Domagala JM, Alessi D, Cummings M, Gracheck S, Huang L. Huband M Johnson G, Olson E, Shapiro M, Singh R, Song Y, Van Bogclen R, Vo D, Wold S (1998) Adv Exp Med Bioi 456:269-286.

13. Takahashi 0, Hiraga K (1981) Toxicol Lett 8:77-86.

14. Tsukioka T, Brock J, Graiser S, Nguyen J, Nakazawa H, Makino T (2003) Anal Sci 19: 151-153.

15. Rigol A, Latorre A, Lacorte S, Barcelo D (2002) J Chromatogr 963:265-275.

16. Inoue K, Wada M, Higuchi T, Oshio S, Umeda T, Yoshimura Y, Nakazawa H (2002) J Chromatogr B 773:97-102.

17. Inoue K, Yamaguchi A, Wada M, Yoshimura Y, Makino T, Nakazawa H (2001) J Chromatogr B 765:121-126.

18. Katayama M, Matsuda $\mathrm{Y}$, Sasaki T, Shimokawa K, Kaneko S, Iwamoto T (2001) Biomed Chromatogr 15:437-442.

19. Sakurai M, Shintani H (2003) Biocontrol Sci 8:69-76. 